\title{
Coupling Automated Electron Backscatter Diffraction with Transmission Electron and Atomic Force Microscopies
}

\author{
A.J. Schwartz, M. Kumar, P.J. Bedrossian, W.E. King
}

This article was submitted to

Microscopy and Microanalysis 2000, Philadelphia, PA, August 1317,2000

\section{January 26, 2000}

U.S. Department of Energy

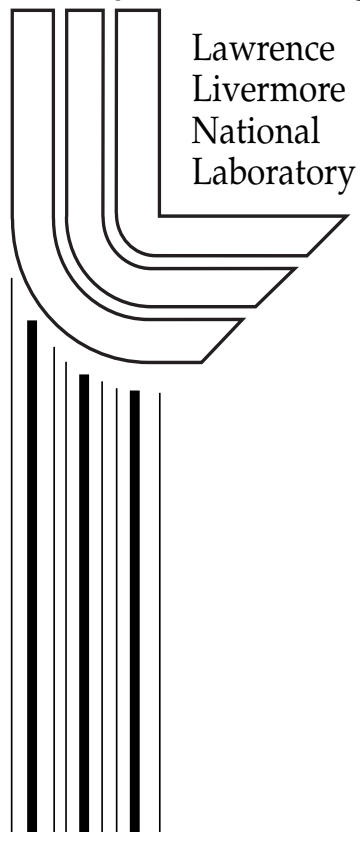




\section{DISCLAIMER}

This document was prepared as an account of work sponsored by an agency of the United States Government. Neither the United States Government nor the University of California nor any of their employees, makes any warranty, express or implied, or assumes any legal liability or responsibility for the accuracy, completeness, or usefulness of any information, apparatus, product, or process disclosed, or represents that its use would not infringe privately owned rights. Reference herein to any specific commercial product, process, or service by trade name, trademark, manufacturer, or otherwise, does not necessarily constitute or imply its endorsement, recommendation, or favoring by the United States Government or the University of California. The views and opinions of authors expressed herein do not necessarily state or reflect those of the United States Government or the University of California, and shall not be used for advertising or product endorsement purposes.

This is a preprint of a paper intended for publication in a journal or proceedings. Since changes may be made before publication, this preprint is made available with the understanding that it will not be cited or reproduced without the permission of the author.

This report has been reproduced

directly from the best available copy.

Available to DOE and DOE contractors from the

Office of Scientific and Technical Information

P.O. Box 62, Oak Ridge, TN 37831

Prices available from (423) 576-8401

http://apollo.osti.gov/bridge/

Available to the public from the

National Technical Information Service

U.S. Department of Commerce

5285 Port Royal Rd.,

Springfield, VA 22161

http://www.ntis.gov/

OR

Lawrence Livermore National Laboratory

Technical Information Department's Digital Library

http://www.llnl.gov/tid/Library.html 


\title{
COUPLING AUTOMATED ELECTRON BACKSCATTER DIFFRACTION WITH TRANSMISSION ELECTRON AND ATOMIC FORCE MICROSCOPIES
}

\author{
A.J. Schwartz, M. Kumar, P.J. Bedrossian, and W.E. King \\ Lawrence Livermore National Laboratory, Chemistry \& Materials Science Directorate, L-355, P.O. Box 808, \\ Livermore, CA 94550 USA
}

Grain boundary network engineering is an emerging field that encompasses the concept that modifications to conventional thermomechanical processing can result in improved properties through the disruption of the random grain boundary network. Various researchers have reported a correlation between the grain boundary character distribution (defined as the fractions of "special" and "random" grain boundaries) and dramatic improvements in properties such as corrosion and stress corrosion cracking, creep, etc. ${ }^{1-3}$ While much early work in the field emphasized property improvements, the opportunity now exists to elucidate the underlying materials science of grain boundary network engineering. Recent investigations at LLNL have coupled automated electron backscatter diffraction (EBSD) ${ }^{4}$ with transmission electron microscopy (TEM) ${ }^{5}$ and atomic force microscopy (AFM) ${ }^{6}$ to elucidate these fundamental mechanisms.

An example of the coupling of TEM and EBSD is given in Figures $1-3$. The EBSD image in Figure 1 reveals "segmentation" of boundaries from special to random and random to special and low angle grain boundaries in some grains, but not others, resulting from the 15\% compression of an Inconel 600 polycrystal. TEM characterization of a similarly deformed sample corroborates both these observations. The grain on the left in Figure 2 is in a soft deformation orientation and exhibits tangles of dislocations while dislocation-rich bands are observed in the grain on the right, which is in a hard deformation orientation. These dislocation-rich bands also interact with the boundary to locally alter the misorientation from near a $\Sigma 91_{\mathrm{d}}$ to near a $\Sigma 37_{\mathrm{c}}$. Such observations validate the initial observation of the segmentation of the boundary observed in the EBSD image of Figure 1. Figure 3 is an example of the effect of annealing twinning on the change in misorientation across a boundary (Fig. 3a) and the formation of a $\Sigma 3, \Sigma 9$, and $\Sigma 27$ triple junction (Fig. 3b) as commonly observed in grain boundary network engineered materials. These fine-scale details are correlated to mesoscopic observations of a high fraction of three special boundaries forming a triple junction (Fig. 3c).

To evaluate the corrosion properties of individual boundaries in various Ni-base alloys, EBSD has been coupled with AFM. Figure 4a is an AFM topological image of an Alloy C-22 sample corroded in HCL for 8 hrs and scanned with EBSD. Corrosion is observed along random boundaries but not at the $\Sigma 3$ boundary. It is interesting to note that the random boundary exhibits different corrosion behavior on either side of the twin boundary. Figure $4 \mathrm{~b}$ is an AFM topological image (depth of corrosion in grey scale) of an electropolished Inconel 600 sample overlaid with a misorientation map indicating special boundaries in black and random boundaries in white. Triple junctions appear to be the preferred sites for the initiation of the earliest stages of localized attack.

This investigation provides evidence that grain boundary network engineering and the formation of annealing twins disrupt the connectivity of the random grain boundary network and is likely responsible for the experimentally observed improvement in properties. This work illustrates that coupling of automated EBSD with other microstructural probes such as TEM and AFM provides data of greater value than any single technique in isolation. The coupled techniques have been applied to aid in understanding the underlying mechanisms of grain boundary network engineering and the corrosion properties of individual boundaries.

\section{References}

1. G. Palumbo, U.S. Patents 5,702,543 (1997) and 5,817,193 (1998).

2. E.M. Lechockey at al., Metallurgical and Materials Transactions, 28A, (1998) 387.

3. G.S. Was et al., Journal of Metals, 50, No. 2 (1998) 44.

4. M. Kumar et al., Advances in Twinning, TMS Annual Meeting, (1999) 13.

5. M. Kumar et al., Presented at MRS Fall Meeting, Interfacial Engineering, (1999).

6. P.J. Bedrossian et al., MRS Fall Meeting, Interfacial Engineering, (1999) in press.

7. This work is performed under the auspices of the US Department of Energy by the Lawrence Livermore National Laboratory under contract W-7405-Eng-48. The authors wish to thank Mr. M. Wall, Ms. L. Nguyen, and Ms. A. Bliss for their technical support. 

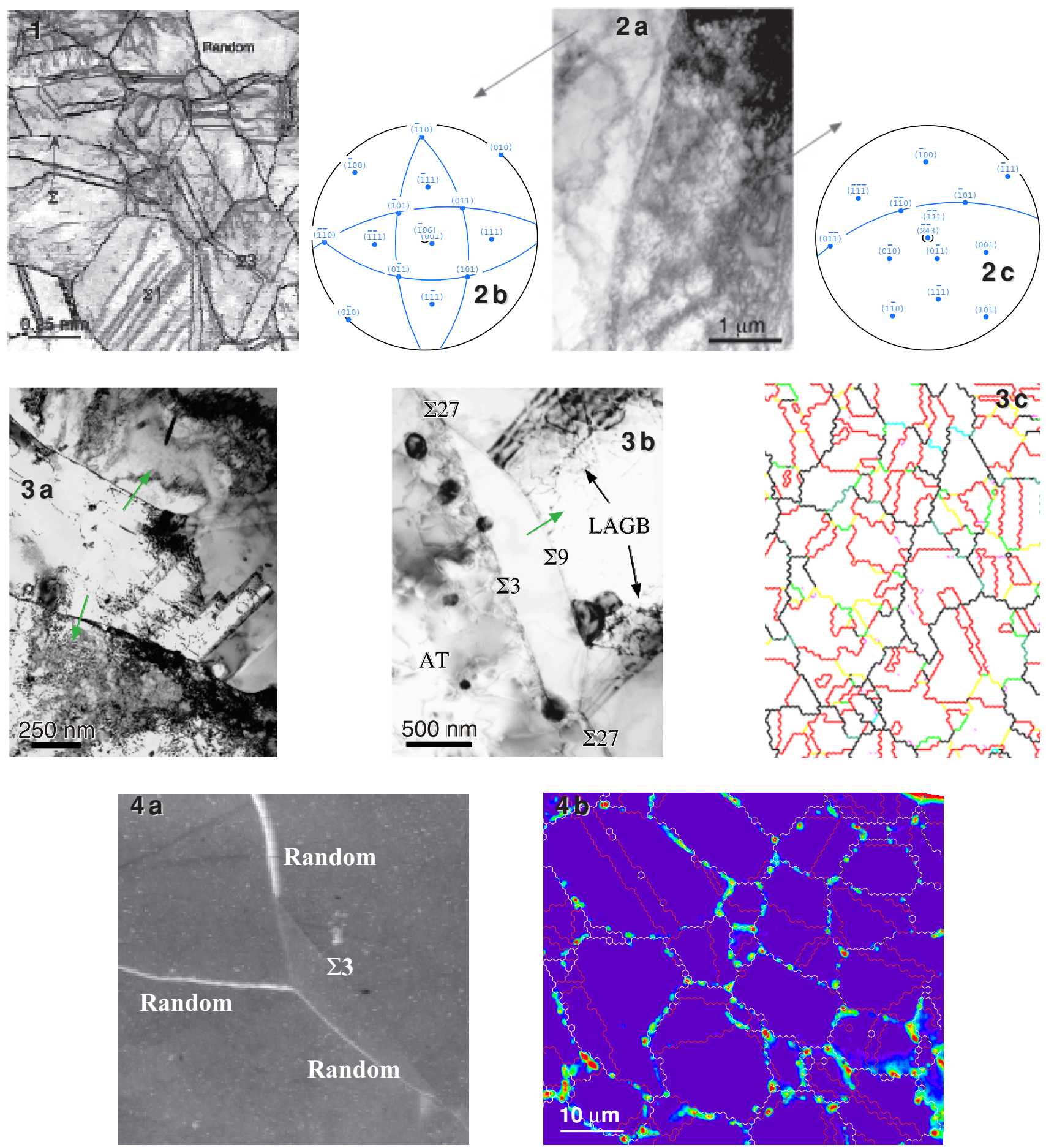

Figure 1. Automated EBSD image of Inconel 600 solution treated and compressed 15\%.

Figure 2. (a) TEM image of a grain boundary for the material in Figure 1, (b and c) stereographic projections indicating the orientation of each grain.

Figure 3. (a) Annealing twins in partially recrystallized Inc600, (b) $\Sigma 3, \Sigma 9$, and $\Sigma 27$ triple junction, and (c) EBSD image revealing a high fraction of 3-special-boundary triple junctions.

Figure 4. (a) AFM image of corroded Alloy C-22, (b) overlay of EBSD image and AFM topological image of electropolished Inconel 600. 